\title{
Sorption and predicted mobility of herbicides in Baltic soils
}

\author{
ONA SAKALIENE ${ }^{1}$, SHARON K. PAPIERNIK ${ }^{2}$, WILLIAM C. KOSKINEN ${ }^{3}$ and KURT A. SPOKAS ${ }^{2}$ \\ ${ }^{1}$ Lithuanian Institute of Agriculture, Vilnius, Lithuania \\ ${ }^{2}$ United States Department of Agriculture-Agricultural Research Service, Morris, Minnesota \\ ${ }^{3}$ United States Department of Agriculture-Agricultural Research Service, St. Paul, Minnesota
}

\begin{abstract}
This study was undertaken to determine sorption coefficients of eight herbicides (alachlor, amitrole, atrazine, simazine, dicamba, imazamox, imazethapyr, and pendimethalin) to seven agricultural soils from sites throughout Lithuania. The measured sorption coefficients were used to predict the susceptibility of these herbicides to leach to groundwater. Soil-water partitioning coefficients were measured in batch equilibrium studies using radiolabeled herbicides. In most soils, sorption followed the general trend pendimethalin $>$ alachlor $>$ atrazine $\sim$ amitrole $\sim$ simazine $>$ imazethapyr $>$ imazamox $>$ dicamba, consistent with the trends in hydrophobicity $\left(\log \mathrm{K}_{\mathrm{ow}}\right)$ except in the case of amitrole. For several herbicides, sorption coefficients and calculated retardation factors were lowest (predicted to be most susceptible to leaching) in a soil of intermediate organic carbon content and sand content. Calculated herbicide retardation factors were high for soils with high organic carbon contents. Estimated leaching times under saturated conditions, assuming no herbicide degradation and no preferential water flow, were more strongly affected by soil textural effects on predicted water flow than by herbicide sorption effects. All herbicides were predicted to be slowest to leach in soils with high clay and low sand contents, and fastest to leach in soils with high sand content and low organic matter content. Herbicide management is important to the continued increase in agricultural production and profitability in the Baltic region, and these results will be useful in identifying critical areas requiring improved management practices to reduce water contamination by pesticides.
\end{abstract}

Keywords: Alachlor; amitrole; atrazine; dicamba; imazamox; imazethapyr; pendimethalin; simazine; adsorption.

\section{Introduction}

Sorption of pesticides to soil controls the pest-control efficacy and environmental fate of pesticides, including the availability of pesticides for microbial degradation and offsite transport by leaching, runoff, and volatilization. Extensive use of pesticides in production agriculture has resulted in their widespread occurrence in surface and ground waters. In areas subject to extensive monitoring, such as the United States and Western Europe, surface and ground waters are found to be widely contaminated with low concentrations of a variety of pesticides. ${ }^{[1,2]}$ In both the United States and Europe, $s$-triazine herbicides and their degradation products are common contaminants of ground water resources. ${ }^{[2,3]}$

Little information is available in the peer-reviewed literature regarding pesticide fate in soils of the Baltic region. A limited survey of Lithuanian water resources conducted in cooperation with the United States Environmental Protection Agency found the insecticide lindane and the herbi-

Address correspondence to Sharon Papiernik, USDA-ARS, Morris, MN 56267; Phone: 320-589-3411; Fax: 320-589-3787; E-mail: Sharon.Papiernik@ars.usda.gov

Received February 13, 2007. cides atrazine, desmetryn, dichlorprop, lenacil, prometryn, propazine, and simazine in ground water; this survey also found the herbicide alachlor in surface water ${ }^{[4]}$ Herbicides, including atrazine and simazine, have been measured in surface water in Poland and in the southern Baltic Sea. ${ }^{[5]}$

Measurements of pesticide sorption are required to predict movement of pesticides following application. Transport models, including GLEAMS (Groundwater Loading Effects of Agricultural Management Systems), LEACHM (Leaching Estimation and Chemistry Model), and Hydrus, typically use equilibrium sorption estimates $\left(\mathrm{K}_{\mathrm{d}}\right)$ or sorption coefficients normalized to the organic carbon content of the soil $\left(\mathrm{K}_{\mathrm{oc}}\right)$ to describe pesticide retention by soil. ${ }^{[6]}$ Accuracy of sorption estimates can be more important than the model choice in accurately simulating pesticide leaching, ${ }^{[6]}$ which emphasizes the need for evaluating pesticide sorption under local conditions. This study was conducted to evaluate the sorption of eight herbicides including alachlor (2-chloro-2',6'-diethyl-Nmethoxymethylacetanilide), amitrole $(1 \mathrm{H}-1,2,4$-triazol3 -amine), atrazine (6-chloro- $\mathrm{N}$-ethyl- $\mathrm{N}^{\prime}$-isopropyl-1,3,5triazine-2,4-diamine), simazine (6-chloro-N,N'-diethyl1,3,5-triazine-2,4-diamine), dicamba (3,6-dichloro-2-methoxybenzoic acid), imazamox (2-[(RS)-4-isopropyl-4-methyl-5-oxo-2-imidazolin-2-yl]-5-methoxymethylnicotinic 
Table 1. Selected properties of soils used in this study: seven Baltic soils collected from throughout Lithuania

\begin{tabular}{lllcrrr}
\hline Location & Texture & $p H$ & Organic carbon (weight \%) & Sand (\%) & Silt (\%) & Clay (\%) \\
\hline Dotnuva & Sandy loam & 7.2 & 2.48 & 55.8 & 25.0 & 19.2 \\
Joniskelis & Silty clay & 6.9 & 1.36 & 5.5 & 48.4 & 42.1 \\
Perloja & Sandy loam & 5.8 & 0.95 & 2.24 & 30.4 & 9.8 \\
Rumokai & Clay & 6.5 & 1.4 & 27.3 & 30.6 & 50.2 \\
Rumokai IX & Silt loam & 6.2 & 1.1 & 53.4 & 35.5 \\
Traku Voke & Sandy loam & 6.1 & 1.37 & 40.7 & 38.1 \\
Vezaiciai & Loam & 5.7 & 19.2 & 21.2 \\
\hline
\end{tabular}

acid), imazethapyr (5-ethyl-2-[(RS)-4-isopropyl-4-methyl5-oxo-2-imidazolin-2-yl]nicotinic acid), and pendimethalin (N-(1-ethylpropyl)-2,6-dinitro-3,4-xylidine). To seven agricultural soils of Lithuania. These herbicides are representative of six chemical classes and are in common use in Lithuania and throughout the Baltic region. The measured sorption coefficients were used to predict the potential mobility of each herbicide in these soils.

\section{Materials and methods}

\section{Soils}

Soils were collected from agricultural fields throughout Lithuania at sampling sites indicated in Figure 1. Samples were collected from the surface $20 \mathrm{~cm}$, air dried, and sieved to $<2 \mathrm{~mm}$. Selected soil properties of each soil are given in Table 1. Soil pH was measured in 1:1 (w:w) soil:0.01 M $\mathrm{CaCl}_{2}$ solution. Organic carbon content was measured using a modified Walkley Black method. ${ }^{[7]}$ Proportions of sand, silt, and clay were determined by the hydrometer method..$^{[8]}$

\section{Chemicals}

Eight herbicides from six chemical classes were used in this study. Selected properties of these herbicides are listed

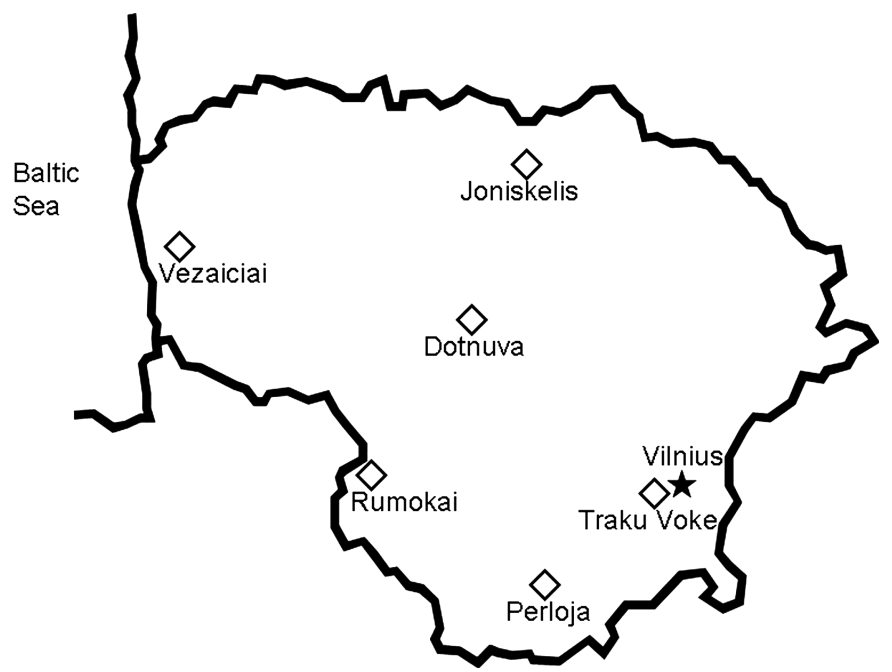

Fig. 1. Sampling sites in Lithuania. in Table 2. Unlabeled analytical chemicals ( $>98 \%$ purity) were obtained from Chem Service, Inc. (West Chester, PA). Radiolabeled (UL-ring- ${ }^{14} \mathrm{C}$ ) compounds were obtained from Pathfinder Laboratories (St. Louis, MO) (alachlor, atrazine, and dicamba), American Cyanamid (Princeton, NJ) (imazamox, imazethapyr, and pendimethalin), Geigy Research Laboratories (Yonkers, NY) (simazine), and Rhone Poulenc (Research Triangle Park, NC) (amitrole). Specific activities ranged from 100 to $999 \mathrm{kBq} \mathrm{mmol}^{-1}$ and all radiopurities were $>97 \%$. Herbicide solutions $\left(1 \mathrm{mg} \mathrm{L}^{-1}\right)$ were prepared in $0.01 \mathrm{M} \mathrm{CaCl}_{2}$. Final solution activities ranged from 1600 to $5980 \mathrm{dpm} \mathrm{mL}{ }^{-1}$.

\section{Sorption}

Solution $(10 \mathrm{~mL})$ containing $1 \mathrm{mg} \mathrm{L}^{-1}$ of a single herbicide was added to triplicate soil samples (5 g dry weight) in 50$\mathrm{mL}$ centrifuge tubes. Dicamba is weakly sorbed, and 10 $\mathrm{g}$ of soil was spiked with $10 \mathrm{~mL}$ of solution to increase the proportion of dicamba removed from solution in an attempt to improve the precision of the sorption estimate. Tubes were capped with a Teflon-lined cover. Vials with no soil served as controls to evaluate sorption to glassware. Samples were agitated using a vortex mixer and placed on a horizontal shaker for $24 \mathrm{~h}$. Equilibrated samples were centrifuged for $30 \mathrm{~min}$ at $2000 \mathrm{rpm}(478 \times \mathrm{g})$. A $1-\mathrm{mL}$ aliquot of the supernatant was transferred to a scintillation vial containing $5 \mathrm{~mL}$ of Ecolite scintillation cocktail (MP Biomedicals, Solon, OH). Vials were shaken for $20 \mathrm{~s}$, and stored in the dark for $24 \mathrm{~h}$ before counting radioactivity using a Packard 1500 Tri-Carb liquid scintillation analyzer.

The difference between the solution activity prior to its addition to soil and the activity after equilibration with soil was attributed to sorption. A sorption coefficient $\left(\mathrm{K}_{\mathrm{d}}, \mathrm{L}\right.$ $\mathrm{kg}^{-1}$ ) was calculated for each herbicide-soil combination by

$$
\mathrm{K}_{\mathrm{d}}=\frac{\mathrm{C}_{\mathrm{s}}}{\mathrm{C}_{\mathrm{w}}}
$$

where $\mathrm{C}_{\mathrm{s}}$ is the concentration of herbicide sorbed to soil $\left(\mathrm{mg} \mathrm{kg}^{-1}\right)$ and $\mathrm{C}_{\mathrm{w}}\left(\mathrm{mg} \mathrm{L}^{-1}\right)$ is the concentration of herbicide in solution at equilibrium. Organic carbon normalized sorption coefficients $\left(\mathrm{K}_{\mathrm{oc}}, \mathrm{L} \mathrm{kg}^{-1}\right)$ were calculated by

$$
\mathrm{K}_{\mathrm{oc}}=\frac{100 \times \mathrm{K}_{\mathrm{d}}}{\mathrm{f}_{\mathrm{oc}}}
$$


Table 2. Selected physical-chemical properties of the herbicides included in these experiments (from Tomlin ${ }^{[26]}$ )

\begin{tabular}{|c|c|c|c|c|c|c|}
\hline Herbicide & Chemical class & $\begin{array}{l}\text { Molecular } \\
\text { weight }\end{array}$ & $\begin{array}{c}\text { Melting } \\
\text { point }\left({ }^{\circ} \mathrm{C}\right)\end{array}$ & $\begin{array}{l}\text { Water solubility } \\
\qquad\left(m g L^{-1}\right)\end{array}$ & $\begin{array}{l}\text { Octanol-water partition } \\
\text { coefficient }\left(\log K_{\text {ow }}\right)\end{array}$ & Acid $p K a$ \\
\hline Alachlor & Chloroacetanilide & 269.8 & $40-42$ & 242 & 3.09 & None \\
\hline Amitrole & Triazole & 84.1 & 159 & 280,000 & -0.97 & 4.2 \\
\hline Atrazine & Chlorotriazine & 215.7 & $175-177$ & 33 & 2.5 & 1.7 \\
\hline Dicamba & Benzoic acid & 221.0 & $114-116$ & 6500 & -0.15 & 1.97 \\
\hline Imazamox & Imidazolinone & 305.3 & $166-167$ & $4100^{*}$ & 0.73 & $3.3^{*}$ \\
\hline Imazethapyr & Imidazolinone & 289.3 & $169-173$ & 1400 & 1.49 & 3.9 \\
\hline Pendimethalin & Dinitroaniline & 281.3 & $47-57$ & 0.3 & 5.18 & None \\
\hline Simazine & Chlorotriazine & 201.7 & $225-227$ & 6.2 & 2.1 & 1.62 \\
\hline
\end{tabular}

${ }^{*}$ Data from Cedergreen et al. ${ }^{[27]}$

where $f_{o c}$ is the weight fraction of organic carbon in the soil. Relationships between soil properties and sorption coefficients were tested by Kendall correlation. Analysis of variance was used to detect differences in sorption coefficients within each soil (differences between eight herbicides) and within each herbicide (differences between seven soils). Significant differences in sorption coefficients were determined using a Tukey test with a probability of Type I error $<0.05$.

\section{Mobility indices}

To provide a first approximation of the tendency for these herbicides to leach in Lithuanian soils, a unitless retardation factor (RF) was estimated for each herbicide in each soil under saturated conditions using

$$
\mathrm{RF}=1+\frac{\rho_{\mathrm{B}} \mathrm{K}_{\mathrm{d}}}{\mathrm{n}}
$$

where $\rho_{\mathrm{B}}$ is the bulk density $\left(\mathrm{g} \mathrm{cm}^{-3}\right)$ of the soil and $\mathrm{n}$ is the total porosity, estimated by

$$
\mathrm{n}=1-\frac{\rho_{\mathrm{B}}}{\rho_{\mathrm{p}}}
$$

where $\rho_{\mathrm{p}}$ is the particle density estimated as $2.65 \mathrm{~g} \mathrm{~cm}^{-3}$. The time (h) required for the peak concentration of each herbicide to occur at $10 \mathrm{~cm}$ depth under saturated flow conditions was estimated assuming no degradation and no preferential flow using

$$
\text { time required to leach to } 10 \mathrm{~cm}=\frac{\mathrm{RF} \times 100 \mathrm{~mm}}{\mathrm{~K}_{\mathrm{s}}}
$$

where $\mathrm{K}_{\mathrm{s}}$ is the saturated hydraulic conductivity $\left(\mathrm{mm} \mathrm{h}^{-1}\right)$ calculated using the pedotransfer functions (PTFs) presented in Saxton and Rawls. ${ }^{[9]}$ Bulk density was estimated by taking the average of four PTFs (Equations 6-9) based on soil texture and organic matter classifications:

$$
\begin{aligned}
\rho_{\mathrm{B}}= & \left(1-\theta_{\mathrm{S}}\right) * 2.65 \text { from Saxton and Rawls }{ }^{[9]} \\
\rho_{\mathrm{B}}= & 1.70398-0.00313(\text { Silt }) \\
& +0.00261(\text { Clay })-0.1855(\mathrm{OM}) \\
& {\text { from Leonavičiūte }{ }^{[10]}}^{[10}
\end{aligned}
$$

$$
\begin{aligned}
\ln \left(\rho_{\mathrm{B}}\right)= & -2.31-1.079 \ln (\mathrm{OM}) \\
& -0.113[\ln (\mathrm{OM})]^{2} \text { from Federer }{ }^{[11]} \text { and } \\
\ln \left(\rho_{\mathrm{B}}\right)= & 0.313-0.382(\mathrm{OM})+0.02102 \text { (Clay) } \\
& -0.000476(\text { Clay })^{2}-0.00432 \text { (Silt) } \\
& {\text { from Kaur et al. }{ }^{[12]}}
\end{aligned}
$$

where Sand, Silt, Clay, and OM are the decimal percentages $(0-1)$ of sand, clay, and organic matter, respectively. $\Theta_{\mathrm{S}}$ is the saturated volumetric moisture content that was estimated from soil texture and organic matter by the relationships in Saxton and Rawls. ${ }^{[9]}$ Organic matter contents were estimated from measured organic carbon contents assuming that the ratio of soil organic matter to soil organic carbon was $1.72 .{ }^{[7]}$

Bernard et al. ${ }^{[13]}$ describe a mobility classification based on RF. They suggest that compounds with a $\mathrm{RF}=1$ are very mobile, those with $\mathrm{RF}>1$ but $<2$ are mobile, those with $\mathrm{RF} \geq 2$ but $<3$ are moderately mobile, those with $\mathrm{RF} \geq 3$ but $<10$ are moderately immobile, and those with $\mathrm{RF} \geq 10$ are very immobile. We used these mobility classifications to indicate the soil-herbicide combinations that might be flagged as most likely to result in groundwater contamination based on the sorption information obtained in these experiments and the estimated total porosity of the soil (Equation 3). These estimated RF values are heavily influenced by equilibrium pesticide sorption results. Because water flow also strongly impacts pesticide transport, the time required to leach each herbicide to $10 \mathrm{~cm}$ depth under saturated flow conditions was also estimated (Equation 5) for each soil.

\section{Results and discussion}

\section{Sorption Coefficients}

A wide range in soil textures were represented by these soils; all had $\geq 1 \%$ organic carbon and tended to be slightly acidic (Table 1). Except for sand and clay content, soil properties were not correlated with one another at $\mathrm{p}<0.05$. Sorption coefficients for pendimethalin were significantly higher $(\alpha=0.05)$ than those for all other herbicides on each 
Table 3. Sorption coefficients (mean \pm standard error) for herbicides on seven Baltic soils*

\begin{tabular}{|c|c|c|c|c|c|c|c|}
\hline \multirow[b]{3}{*}{ Herbicide } & \multicolumn{7}{|c|}{ Soil } \\
\hline & Dotnuva & Joniskelis & Perloja & Rumokai & Rumokai IX & Traku Voke & Vezaiciai \\
\hline & \multicolumn{7}{|c|}{$K_{d}\left(L k^{-1}\right)$} \\
\hline Alachlor & $3.36 \pm 0.003 \mathrm{a}$ & $2.24 \pm 0.07 \mathrm{c}$ & $1.5 \pm 0.1 \mathrm{e}$ & $2.59 \pm 0.04 b$ & $1.70 \pm 0.04 \mathrm{de}$ & $1.74 \pm 0.03 \mathrm{de}$ & $1.91 \pm 0.08 \mathrm{~d}$ \\
\hline Amitrole & $0.83 \pm 0.03 \mathrm{a}$ & $0.95 \pm 0.02 \mathrm{a}$ & $0.68 \pm 0.007 \mathrm{~b}$ & $0.92 \pm 0.007 \mathrm{a}$ & $0.40 \pm 0.02 \mathrm{c}$ & $0.87 \pm 0.04 \mathrm{a}$ & $0.93 \pm 0.05 \mathrm{a}$ \\
\hline Atrazine & $0.9 \pm 0.3 \mathrm{~b}$ & $1.09 \pm 0.02 \mathrm{ab}$ & $1.04 \pm 0.02 \mathrm{ab}$ & $1.50 \pm 0.06 \mathrm{a}$ & $0.86 \pm 0.02 b$ & $0.18 \pm 0.02 \mathrm{c}$ & $1.35 \pm 0.09 \mathrm{ab}$ \\
\hline Dicamba & $0.07 \pm 0.009 \mathrm{a}$ & $0.05 \pm 0.01 \mathrm{ab}$ & $0.08 \pm 0.004 \mathrm{a}$ & $0.03 \pm 0.001 \mathrm{~b}$ & $0.05 \pm 0.002 \mathrm{ab}$ & $0.07 \pm 0.008 \mathrm{a}$ & $0.05 \pm 0.008 \mathrm{ab}$ \\
\hline Imazamox & $0.26 \pm 0.009 \mathrm{bc}$ & $0.42 \pm 0.02 \mathrm{a}$ & $0.33 \pm 0.03 b$ & $0.30 \pm 0.02 \mathrm{~b}$ & $0.19 \pm 0.006 \mathrm{c}$ & $0.28 \pm 0.008 \mathrm{~b}$ & $0.26 \pm 0.02 \mathrm{bc}$ \\
\hline Imazethapyr & $0.60 \pm 0.01 \mathrm{ab}$ & $0.67 \pm 0.009 \mathrm{ab}$ & $0.59 \pm 0.02 \mathrm{ab}$ & $0.7 \pm 0.1 \mathrm{a}$ & $0.32 \pm 0.01 \mathrm{c}$ & $0.50 \pm 0.008 \mathrm{bc}$ & $0.59 \pm 0.01 \mathrm{ab}$ \\
\hline Pendimethalin & $153 \pm 11 \mathrm{a}$ & $83 \pm 4 d$ & $75 \pm 2 \mathrm{~d}$ & $91 \pm 1 \mathrm{~cd}$ & $83 \pm 4 d$ & $115 \pm 5 b c$ & $131 \pm 5 \mathrm{ab}$ \\
\hline Simazine & $1.35 \pm 0.03 \mathrm{a}$ & $0.71 \pm 0.02 \mathrm{de}$ & $0.66 \pm 0.01 \mathrm{e}$ & $1.05 \pm 0.06 \mathrm{~b}$ & $0.35 \pm 0.01 \mathrm{f}$ & $0.88 \pm 0.01 \mathrm{c}$ & $0.83 \pm 0.02 \mathrm{~cd}$ \\
\hline
\end{tabular}

*For each herbicide, values followed by different lowercase letters are significantly different $(\alpha=0.05)$.

soil; $\mathrm{K}_{\mathrm{d}}$ values for pendimethalin were at least one order of magnitude greater than those for the other herbicides (Table 3). Except for the Traku Voke soil, sorption coefficients followed the trend pendimethalin $>$ alachlor $>$ atrazine $\sim$ amitrole $\sim$ simazine $>$ imazethapyr $>$ imazamox $>$ dicamba (Table 3). The Traku Voke soil followed the same general trends, except that atrazine $\mathrm{K}_{\mathrm{d}}$ values were low in this soil (Table 3). This trend generally agrees with the trends in log $\mathrm{K}_{\mathrm{ow}}$ values (Table 2), except in the case of amitrole, which has a low $\mathrm{K}_{\mathrm{ow}}$ (Table 2), but sorption similar to the triazine herbicides in these soils (Table 3).

Sorption coefficients for alachlor, pendimethalin and simazine were significantly correlated $(\mathrm{p}<0.05)$ with organic carbon contents, but $K_{d}$ values for the remaining five herbicides were not correlated with the weight fraction of organic carbon in soil. Because organic carbon is widely identified as the primary sorbent of hydrophobic organic compounds, ${ }^{[14]} \mathrm{K}_{\mathrm{oc}}$ values are often observed to be less variable than $\mathrm{K}_{\mathrm{d}}$ values. In this study, organic-carbon normalized sorption coefficients $\left(\mathrm{K}_{\mathrm{oc}}\right)$ were less variable than $\mathrm{K}_{\mathrm{d}}$ values across the seven soils only for the triazine (atrazine and simazine) and chloroacetanilide (alachlor) herbicides.
For all other herbicides, $\mathrm{K}_{\mathrm{oc}}$ values were more variable than $K_{d}$ values, but for both $K_{d}$ (Table 3 ) and $K_{o c}$, values varied by less than an order of magnitude. The ratio of maximum to minimum $\mathrm{K}_{\mathrm{oc}}$ values ranged from 1.4 for alachlor to 6.6 for atrazine, a variability that is commonly observed in surface soils. ${ }^{[14]}$ These results suggest that organic carbon may not be the sole sorbent in these soils and/or the organic matter in these soils may have differing sorptivities to these herbicides. The processes influencing differential herbicide sorption in these soils were not investigated, and a number of factors can affect the variation in sorption coefficients. ${ }^{[14]}$

Sorption coefficients for alachlor, amitrole, atrazine, and imazethapyr were positively correlated with clay content, whereas dicamba sorption was negatively correlated with clay content (Table 4). Experimental evidence has shown that sorption of neutral organics (such as these herbicides) to natural sediments is generally not significantly affected by mineral contributions until the ratio of clay minerals to organic carbon is $\sim 30$ or greater ${ }^{[15]}$ In this study, only one soil (Joniskelis) had a relatively high ratio of claysized particles to organic carbon content (Table 1), and only for imazamox did this soil have significantly higher

Table 4. Kendall correlation coefficients between herbicide sorption coefficients $\left(\mathrm{K}_{\mathrm{d}}\right)$ and soil properties*

\begin{tabular}{|c|c|c|c|c|c|}
\hline & \multicolumn{5}{|c|}{ Soil property } \\
\hline & $\begin{array}{c}\text { Organic } \\
\text { carbon }(\%)\end{array}$ & $p H$ & Sand $(\%)$ & Silt (\%) & Clay (\%) \\
\hline Alachlor $\mathrm{K}_{\mathrm{d}}$ & $0.59(0.0003)$ & $0.50(0.002)$ & $-0.23(0.1)$ & $-0.30(0.06)$ & $0.56(0.0007)$ \\
\hline Amitrole $\mathrm{K}_{\mathrm{d}}$ & $0.02(0.9)$ & $0.09(0.5)$ & $-0.40(0.01)$ & $-0.01(0.9)$ & $0.45(0.006)$ \\
\hline Atrazine $\mathrm{K}_{\mathrm{d}}$ & $0.24(0.1)$ & $-0.02(0.9)$ & $-0.20(0.2)$ & $-0.17(0.3)$ & $0.49(0.003)$ \\
\hline Dicamba $\mathrm{K}_{\mathrm{d}}$ & $-0.31(0.05)$ & $-0.14(0.4)$ & $0.59(0.003)$ & $-0.23(0.1)$ & $-0.57(0.0005)$ \\
\hline Imazamox $\mathrm{K}_{\mathrm{d}}$ & $-0.25(0.1)$ & $0.13(0.4)$ & $-0.06(0.7)$ & $-0.11(0.5)$ & $0.10(0.5)$ \\
\hline Imazethapyr $\mathrm{K}_{\mathrm{d}}$ & $0.04(0.8)$ & $0.17(0.3)$ & $-0.16(0.3)$ & $-0.23(0.1)$ & $0.37(0.02)$ \\
\hline Pendimethalin $\mathrm{K}_{\mathrm{d}}$ & $0.38(0.02)$ & $0.05(0.7)$ & $0.19(0.2)$ & $-0.27(0.1)$ & $0.10(0.5)$ \\
\hline Simazine $\mathrm{K}_{\mathrm{d}}$ & $0.41(0.01)$ & $0.30(0.06)$ & $0.12(0.4)$ & $-0.66(0.0001)$ & $0.19(0.2)$ \\
\hline
\end{tabular}

*Values in parentheses are $\mathrm{p}$ values. 
$\mathrm{K}_{\mathrm{d}}$ values than other soils (Table 3 ). No significant correlation between $K_{d}$ and clay content was observed for alachlor, atrazine, imazethapyr, or dicamba sorption to tropical soils. ${ }^{[16]}$ Numerous studies have demonstrated specific herbicide-clay mineral interactions. ${ }^{[15]}$ Clay mineralogy and the availability of mineral surfaces in the soil were not determined in this study, so the mechanistic significance of a statistical correlation between sorption coefficients and clay content is not known. Alachlor was the only herbicide for which sorption was significantly correlated with $\mathrm{pH}$ (Table 4). Alachlor is not ionizable (Table 2). The soils included in this study tended to be slightly acidic and varied over a relatively small range in $\mathrm{pH}$ ( $\mathrm{pH} 5.7$ to 7.2 , Table 1 ). The correlation of alachlor $\mathrm{K}_{\mathrm{d}}$ and soil $\mathrm{pH}$ is expected to be due to the relationship between organic carbon and $\mathrm{pH}$ (correlated with $p<0.1$ ) and the strong influence of organic carbon in alachlor sorption.

Atrazine and alachlor have been heavily-used in many agricultural areas; they are frequently detected in ground and surface waters ${ }^{[1,2]}$ and these herbicides are well-studied. In these experiments, the alachlor $\mathrm{K}_{\mathrm{d}}$ was 1.4 to 10 times higher than the atrazine $\mathrm{K}_{\mathrm{d}}$ in each soil (Table 3). Other studies evaluating atrazine and alachlor sorption in the same soils have indicated that alachlor is often more highly sorbed than atrazine in a variety of soils from temperate ${ }^{[17-19]}$ and tropical regions. ${ }^{[13,16,20]}$ Many studies evaluating the sorption of multiple pesticides to a soil include atrazine, providing a basis for comparative sorption estimates. In the present study, dicamba had $\mathrm{K}_{\mathrm{d}}$ values 3 to 50 times lower than those for atrazine in all soils (Table 3), in agreement with previous studies that reported dicamba $K_{d}$ values that were 4 to 16 times lower than those for atrazine in surface soils. ${ }^{[21]}$ Pendimethalin sorption co- efficients were $>60$ times higher than those for atrazine (Table 3), in agreement with previous observations. ${ }^{[22]}$ In these studies, simazine $K_{d}$ values were generally similar to atrazine $\mathrm{K}_{\mathrm{d}}$ values, as has been observed in other soils. ${ }^{[22,23]}$ All other herbicides (imazamox, imazethapyr, and amitrole) were sorbed to a greater extent than atrazine in the Traku Voke soil and to a lesser extent in all other soils (Table 3). Other studies of comparative sorption have shown results similar to those presented here, including greater sorption of imazethapyr than of imazamox ${ }^{[24]}$ and greater sorption of pendimethalin than of simazine. ${ }^{[22]}$

\section{Mobility Indices}

Estimated retardation factors provide a preliminary indication of the potential for these herbicides to leach in these soils. The mean precipitation (1960-1990) was obtained from Rawlins and Willmott ${ }^{[25]}$ for each site from which soil was collected. These records indicate that rainfall in spring and early summer, when herbicides are most likely to be applied, is relatively consistent among these sites. The mean total precipitation occurring at each site is 26 to $31 \mathrm{~mm}$ in March, 37 to $39 \mathrm{~mm}$ in April, 55 to $64 \mathrm{~mm}$ in May, 55 to $70 \mathrm{~mm}$ in June, and 75 to $81 \mathrm{~mm}$ in July. Since rainfall is relatively consistent among these sites, water transport and herbicide sorption and degradation may be the primary drivers of differential herbicide leaching at these sites. Estimated RFs were calculated for saturated soils to give a preliminary estimate of herbicide retention by these soils (Table 5). Due to the large influence of $\mathrm{K}_{\mathrm{d}}$ on calculated RF, all herbicides were predicted to be susceptible to leaching (low RF, Table 5) in the Rumokai IX soil, which has intermediate organic carbon content and sand content (Table 1)

Table 5. Estimated retardation factor and time required to leach $10 \mathrm{~cm}$ under saturated conditions.

\begin{tabular}{|c|c|c|c|c|c|c|c|c|}
\hline \multirow[b]{2}{*}{ Herbicide } & & \multicolumn{7}{|c|}{ Soil } \\
\hline & & Dotnuva & Joniskelis & Perloja & Rumokai & Rumokai IX & Traku Voke & Vezaiciai \\
\hline \multirow[t]{2}{*}{ Alachlor } & Retardation factor & 12 & 8.2 & 5.6 & 9.8 & 6.4 & 6.4 & 7.1 \\
\hline & Time to leach $10 \mathrm{~cm}(\mathrm{~h})$ & 89 & 620 & 12 & 1100 & 68 & 23 & 59 \\
\hline \multirow[t]{2}{*}{ Amitrole } & Retardation factor & 3.7 & 4.0 & 3.1 & 4.1 & 2.3 & 3.7 & 4.0 \\
\hline & Time to leach $10 \mathrm{~cm}(\mathrm{~h})$ & 28 & 310 & 6.8 & 470 & 24 & 13 & 33 \\
\hline \multirow[t]{2}{*}{ Atrazine } & Retardation factor & 4.1 & 4.5 & 4.3 & 6.1 & 3.7 & 1.5 & 5.3 \\
\hline & Time to leach $10 \mathrm{~cm}(\mathrm{~h})$ & 31 & 340 & 9.2 & 700 & 40 & 5.6 & 44 \\
\hline \multirow[t]{2}{*}{ Dicamba } & Retardation factor & 1.2 & 1.2 & 1.3 & 1.1 & 1.2 & 1.2 & 1.2 \\
\hline & Time to leach $10 \mathrm{~cm}(\mathrm{~h})$ & 9.2 & 88 & 2.7 & 130 & 12 & 4.3 & 9.5 \\
\hline \multirow[t]{2}{*}{ Imazamox } & Retardation factor & 1.8 & 2.3 & 2.0 & 2.0 & 1.6 & 1.9 & 1.8 \\
\hline & Time to leach $10 \mathrm{~cm}(\mathrm{~h})$ & 14 & 180 & 4.4 & 230 & 17 & 6.7 & 15 \\
\hline \multirow[t]{2}{*}{ Imazethapyr } & Retardation factor & 3.0 & 3.1 & 2.9 & 3.4 & 2.0 & 2.5 & 2.9 \\
\hline & Time to leach $10 \mathrm{~cm}(\mathrm{~h})$ & 22 & 240 & 6.2 & 390 & 22 & 9.1 & 24 \\
\hline \multirow[t]{2}{*}{ Pendimethalin } & Retardation factor & 500 & 270 & 240 & 310 & 260 & 360 & 420 \\
\hline & Time to leach $10 \mathrm{~cm}(\mathrm{~h})$ & 3700 & 20,000 & 510 & 36,000 & 2800 & 1300 & 3500 \\
\hline \multirow[t]{2}{*}{ Simazine } & Retardation factor & 5.4 & 3.3 & 3.1 & 4.6 & 2.1 & 3.7 & 3.7 \\
\hline & Time to leach $10 \mathrm{~cm}(\mathrm{~h})$ & 40 & 250 & 6.7 & 520 & 23 & 13 & 30 \\
\hline
\end{tabular}


and low herbicide $\mathrm{K}_{\mathrm{d}}$ (Table 3 ). High RF values were calculated for soils with high organic carbon contents (Table 1) and high herbicide $\mathrm{K}_{\mathrm{d}}$, the Dotnuva and Rumokai soils (Tables 3 and 5).

The RF as calculated here is a function of sorption and soil properties (primarily soil texture as it affects bulk density and volumetric water content at saturation). Retardation factors for all herbicides were strongly positively correlated with $\mathrm{K}_{\mathrm{d}}$, so that the estimated RF increased with increasing sorption for these herbicides. Soil organic carbon content and sand content are often cited as important factors influencing pesticide mobility. In this study, estimated RFs were not correlated with organic carbon contents for any herbicide $(p>0.05)$ and were only significantly correlated with sand content for dicamba (with a positive correlation, indicating that dicamba was predicted to be less mobile in soils with higher sand contents).

Using a mobility classification based on retardation factors ${ }^{[13]}$ for saturated conditions, pendimethalin was predicted to be very immobile in all soils. Dicamba was classified as mobile in all soils. Alachlor, amitrole, atrazine, and simazine were predicted to be moderately immobile in all soils except Dotnuva (alachlor very immobile), Traku Voke (atrazine mobile) and Rumoaki IX (amitrole and simazine moderately mobile). The predicted mobility of imazamox ranged from moderately mobile (3 soils) to mobile (4 soils), whereas imazethapyr's classification ranged from moderately immobile (3 soils) to moderately mobile (4 soils).

Predicting mobility based on RF (heavily influenced by sorption estimates) is only a partial consideration of pesticide transport. Water flow through soil is also an important factor affecting pesticide leaching. Matrix flow of water through each soil under saturated conditions was estimated using a saturated hydraulic conductivity $\left(\mathrm{K}_{\mathrm{s}}\right)$ calculated using PTFs relating soil texture and organic matter to hydraulic conductivity. ${ }^{[9]}$ The time required for each pesticide to leach $10 \mathrm{~cm}$ was estimated using Equation 5, which assumes no preferential flow, no herbicide degradation, and saturated flow conditions, giving a conservative estimate of the risk of pesticide leaching. In these soils, $\mathrm{K}_{\mathrm{s}}$ increased with increasing sand content and with decreasing clay content $(\mathrm{p}<0.05)$. The time required to leach $10 \mathrm{~cm}$ was strongly affected by soil bulk density and clay content (positive correlations, $\mathrm{p}<0.05$ ) for all herbicides, but only for amitrole did the leaching time significantly increase with increasing RF. These estimated leaching times are more strongly affected by soil textural effects on predicted water flow than by herbicide sorption effects. All herbicides were predicted to be slowest to leach in soils with high clay content, low sand content, and low $\mathrm{K}_{\mathrm{s}}$ (Rumokai and Joniskelis) and fastest to leach in soils with high sand content and low organic matter content (Perloja and Traku Voke) (Table 5).

Mobility classifications based on pesticide sorption did not always agree with the time required to leach the herbicide $10 \mathrm{~cm}$ under saturated conditions. For example, dicamba was predicted to be mobile in all soils, with calcu- lated RF values ranging from 1.1 to 1.3 (Table 5). However, because of predicted differences in water flow, the time required for dicamba to leach $10 \mathrm{~cm}$ under saturated conditions ranged from about $3 \mathrm{~h}$ to more than $5 \mathrm{~d}$ (Table 5 ). In contrast, a herbicide-soil combination that was predicted to be very immobile (alachlor in Dotnuva soil) was predicted to leach $10 \mathrm{~cm}$ in approximately $90 \mathrm{~h}$, less than the time required for alachlor leaching in high-clay soils with lower predicted RF (Table 5), and less than a herbicide with very low sorption (dicamba in Rumokai soil, Table 5). These results indicate that the sorption and mobility of these eight herbicides in these Lithuanian soils may not easily be discerned a priori based on soil properties. Additional experimentation is needed to more completely evaluate pesticide fate in these soils and other soils under conditions typical of the Baltic region.

\section{Conclusion}

This study, which evaluated the sorption of eight herbicides to soils representative of Lithuanian agricultural soils, provides preliminary information concerning areas prone to pesticide non-point contamination of water resources. Herbicide sorption coefficients generally followed the trend pendimethalin $>$ alachlor $>$ atrazine $\sim$ amitrole $\sim$ simazine $>$ imazethapyr $>$ imazamox $>$ dicamba. Sorption coefficients were variable among soils, and were correlated with the weight fraction of organic carbon in soil only for alachlor, pendimethalin and simazine. Estimated mobility under saturated conditions indicated that most herbicides were predicted to be most mobile in a soil of intermediate organic carbon content and sand content. Soil textural effects on water flow may have a large impact on pesticide transport. Under saturated conditions, all herbicides were predicted to be slowest to leach in soils with high clay and low sand contents, and fastest to leach in soils with high sand content and low organic matter content. Agricultural production in the Baltic region is rapidly developing, and herbicide management will be important to the continued increase in agricultural production and profitability in this region. These results will be useful in developing improved pesticide management practices to reduce water contamination by pesticides.

\section{References}

[1] Gilliom, R.J.; Barbash, J.E.; Kolpin, D.W.; Larson, S.J. Testing water quality for pesticide pollution. Environ. Sci. Technol. 1999, 33(7), 164A-169A.

[2] Scheidleder, A.; Grath, J.; Winkler, G.; Stärk, U.; Koreimann, C.; Gmeiner, C.; Nixon, S.; Casillas, J.; Gravesen, P.; Leonard, J.; Elvira, M. Pressures on Groundwater Quality. In Groundwater quality and quantity in Europe, Environmental Assessment Report 3; European Environment Agency: Copenhagen, Denmark, 1999; 18-38. 
[3] Barbash, J.E.; Thelin, G.P.; Kolpin, D.W.; Gilliom, R.J. Major herbicides in ground water: Results from the National Water-Quality Assessment. J. Environ. Qual. 2001, 30(3), 831-845.

[4] Ellington, J.J.; Thurston, R.V.; Sukyte, J.; Kvietkus, K. Hazardous chemicals in waters of Lithuania. Trends Anal. Chem. 1996, 15(6), 215-224.

[5] Pempkowiak, J.; Tronczynski, J.; Pazdro, K. Spatial and temporal gradients of triazines in the Baltic Sea off Poland. Mar. Pollut. Bull. 2000, 40(12), 1082-1089.

[6] Dann, R.L.; Close, M.E.; Lee, R.; Pang, L. Impact of data quality and model complexity on prediction of pesticide leaching. J. Environ. Qual. 2006, 35(2), 628-640.

[7] Nelson, D.W.; Sommers, L.E. Total carbon, organic carbon, and organic matter. In Methods of Soil Analysis, Part 2; Page, A.L., Ed.; American Society of Agronomy and Soil Science Society of America: Madison, WI, 1982; 539-577.

[8] Gee, G.W.; Bauder, J.W. Particle-size analysis. In Methods of Soil Analysis, Part 1; Klute, A., Ed.; American Society of Agronomy and Soil Science Society of America: Madison, WI, 1988; 383-441.

[9] Saxton, K.E.; Rawls, W.J. Soil water characteristic estimates by texture and organic matter for hydrologic solutions. Soil Sci. Soc. Am. J. 2006, 70(5), 1569-1578.

[10] Leonavičiūte, N. Predicting soil bulk and particle densities by pedotransfer functions from existing soil data in Lithuania. Geografijos metraštis (The Geographical Yearbook) 2000, 33, 317-330.

[11] Federer, C.A. Nitrogen mineralization and nitrification: Depth variation in four New England forest soils. Soil Sci. Soc. Am. J. 1983, 47(5), 1008-1014.

[12] Kaur, R.; Kumar, S.; Gurung, H.P. A pedo-transfer function (PTF) for estimating bulk density from basic soil data and its comparison with existing PTFs. Austr. J. Soil Res. 2002, 40(5), 847-858.

[13] Bernard, H.; Chabalier, P.F.; Chopart, J.L.; Legube, B.; Vauclin, M. Assessment of herbicide leaching risk in two tropical soils of Reunion Island (France). J. Environ. Qual. 2005, 34(2), 534-543.

[14] Wauchope, R.D.; Yeh, S.; Linders, J.B.H.J.; Kloskowski, R.; Tanaka, K.; Rubin, B.; Katayama, A.; Kördel, W.; Gerstl, Z.; Lane, M.; Unsworth, J.B. Pesticide soil sorption parameters: theory, measurement, uses, limitations and reliability. Pest Manag. Sci. 2002, 58(5), $419-445$.
[15] Karickhoff, S.W. Organic pollutant sorption in aquatic systems. J. Hydraul. Eng. 1984 110(6), 707-735.

[16] Oliveira, R.S., Jr.; Koskinen, W.C.; Ferreira, F.A. Sorption and leaching potential of herbicides on Brazilian soils. Weed Res. 2001, 4l(2), 97-110.

[17] Grundl, T.; Small, G. Mineral contributions to atrazine and alachlor sorption in soil mixtures of variable organic carbon and clay content. J. Contam. Hydrol. 1993, 14(2), 117-128.

[18] Sonon, L.S.; Schwab, A.P. Adsorption characteristics of atrazine and alachlor in Kansas soils. Weed Sci. 1995, 43(3), 461-466.

[19] Walker, A.; Welch, S.J.; Melacini, A.; Moon, Y.H. Evaluation of three pesticide leaching models with experimental data for alachlor, atrazine, and metribuzin. Weed Res. 1996, 36(1), 37-47.

[20] Laabs, V.; Amelung, W. Sorption and aging of corn and soybean pesticides in tropical soils of Brazil. J. Agric. Food Chem. 2005, 53(18), 7184-7192.

[21] Johnson, R.M.; Sims, J.T. Influence of surface and subsoil properties on herbicide sorption by Atlantic Coastal Plain soils. Soil Sci. 1993, 155(5), 339-348.

[22] Barriuso, E.; Houot, S.; Serra-Wittling, C. Influence of compost addition to soil on the behaviour of herbicides. Pestic. Sci. 1997, 49(1), 65-75.

[23] Gerritse, R.G.; Beltran, J.; Hernandez, F. Adsorption of atrazine, simazine, and glyphosate in soils of the Gnangara Mound, Western Australia. Austr. J. Soil. Res. 1996, 34(4), 599-607.

[24] Aichele, T.M.; Penner, D. Adsorption, desorption, and degradation of imidazolinones in soil. Weed Technol. 2005, 19(1), 154 159.

[25] Rawlins, M.A.; Willmott, C.J. Arctic land-surface precipitation: 1960-1990 gridded monthly time series, version 1.01. University of Delaware Center for Climatic Research. http://climate. geog.udel.edu/ climate/index.shtml (accessed March 2007).

[26] Tomlin, C.D.S., Ed. The Pesticide Manual: A World Compendium; British Crop Protection Council: Farnham, Surrey, UK, 1997; $1606 \mathrm{pp}$.

[27] Cedergreen, N.; Andersen, L.; Olesen, C.F.; Spliid, H.H.; Streibig, J.C. Does the effect of herbicide pulse exposure on aquatic plants depend on $\mathrm{K}_{\mathrm{ow}}$ or mode of action? Aquat. Toxicol. 2005, 71(3), 261-271. 